\title{
Patient Satisfaction After Hand Trauma Surgery Performed Under Regional Anaesthesia
}

\author{
D. Buckley ${ }^{1}$, S. Ahmed ${ }^{1}$, S. Khan ${ }^{1}$, H. Krishnamurthy ${ }^{1}$ \\ ${ }^{1}$ Department of Anaesthesia, Royal Victoria Infirmary, Newcastle upon Tyne, UK
}

\section{Background}

It is established that use of regional anaesthesia as the sole anaesthetic method results in faster recovery and superior pain relief ${ }^{1}$, whilst having fewer side effects and high patient saisfaction ${ }^{2}$. This study follows on from a previous audit analysing data following hand surgery performed under regional anaesthesia.

\section{Methods}

Pain scores, satisfaction rates and complications were reviewed from patients who received a block for hand trauma surgery since 2012.

\section{Results}

Of the 1838 patients who had complete data, mean age was $42,68 \%$ were male and $95 \%$ ASA $1-2$.

The majority were day case procedures $(92 \%)$ lasting $<2$ hours (99\%). Axillary blocks were most common (78\%), followed by infraclavicular blocks (16\%). Forearm top-up blocks occurred in $9 \%$. The intra-operatively quality of the block was "perfect" in $94 \%$ of cases.

Whilst motor weakness was rated as "a little annoying" by $21 \%$ of patients, the majority $(72 \%)$ did not find it an issue. No pain was experienced by $94 \%$ of patients on the postoperative ward, dropping to $74 \%$ and $57 \%$ in the evening and night of surgery, respectively (see graph 1).

\section{Graph 1: Pain Scores}

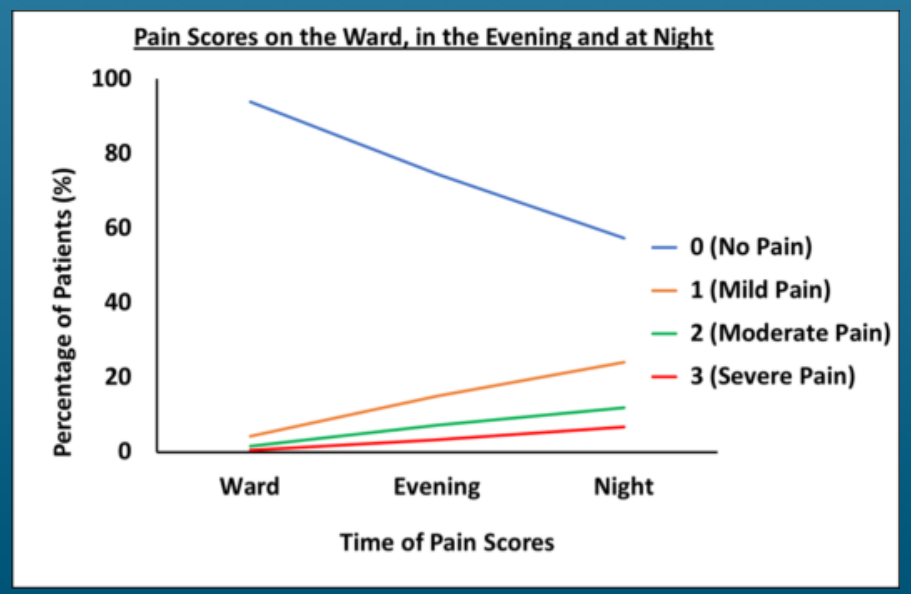

Most were performed without sedation (86\%) and few patients felt pain or paraesthesia during the block ( $1 \%$ and $5 \%$, respectively), with $77 \%$ describing the experience as "not unpleasant".

Overall, $91 \%$ of patients reported satisfaction rates of good or excellent, with $92 \%$ saying they would have regional anaesthesia again.

\section{Graph 2: Overall Patient Satisfaction}

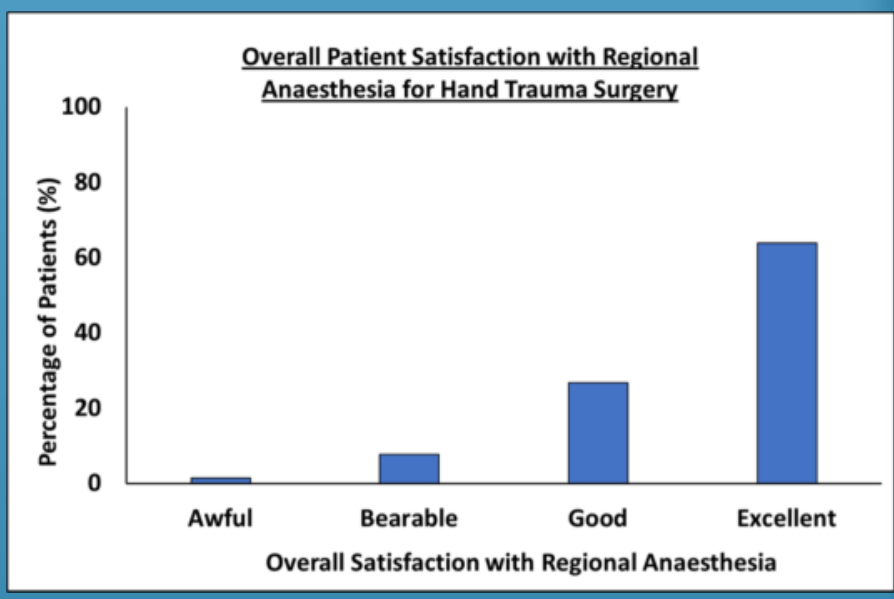

The complication rate was very low and, in most cases, found to be due to the primary injury or surgery rather than the regional block.

\section{Conclusions}

Use of regional anaesthesia for hand trauma patients produces excellent results in the majority of patients.

This, along with the low complication rates, suggests that routine follow-up is unlikely to be needed in the future.

\section{Acknowledgements}

Many thanks to the acute pain team at the Royal Victoria Infirmary who followed the patients up and entered and maintained the data on the acute pain database.

\section{References}

1. Hadzic A, Williams BA, Karaca PE, Hobeika P, Unis G, Dermksian J, Yufa M, Thys DM, Santos AC. For outpatient rotator cuff surgery, nerve block anesthesia provides superior same-day recovery over general anesthesia. Anesthesiology 2005; 102: 1001-7.

2. Klein SM, Nielsen KC, Greengrass RA, Warner DS, Martin A, Steele SM. Ambulatory discharge after long-acting peripheral nerve blockade: 2382 blocks with ropivacaine. Anesthesia \& Analgesia 2002; 94: 65-70. 